ISSN: $1130-2887$

\title{
CRISIS DE LA REPÚBLICA DELEGATIVA. LA CONSTITUCIÓN DE NUEVOS ACTORES POLÍTICOS EN LA ARGENTINA (2001-2003): LAS ASAMBLEAS VECINALES Y POPULARES
}

\author{
Crisis of the delegative Republic. The constitution of new political \\ actors in Argentina (2001-2003): neighbourbood and popular \\ assemblies
}

\author{
Federico Matías RossI \\ Instituto de Investigaciones Gino Germani, Universidad de Buenos Aires \\ 凶federicomatiasrossi@yahoo.com.ar
}

BIBLID [1130-2887 (2005) 39, 195- $<16$ ]

Fecha de recepción: febrero del 2004

Fecha de aceptación y versión final: marzo del 2004

RESUMEN: Los días 19 y 20 de diciembre de 2001 se produjo la protesta social más importante que ha vivido la Argentina democrática reciente. La irresolución del reequilibramiento institucional durante los primeros meses del estallido abre las oportunidades políticas para la conformación de un nuevo actor político, el movimiento asambleario, el cual será central hasta el reacomodamiento del sistema institucional con la elección presidencial de abril de 2003 . El objetivo es estudiar desde su origen las novedosas características que asumirá este movimiento en toda su complejidad. Para ello, se analizará el estudio etnográfico realizado de enero de 2002 a febrero de 2003 en dos casos, la Asamblea Vecinal de Palermo Viejo y la Asamblea Popular Cid Campeador; los cuales se presentan como representativos de los dos grupos que conformarán al movimiento, y que definirán su identidad, estructura de organización, así como los repertorios de acción colectiva.

Palabras clave: Argentina, movimientos sociales, protesta social, asambleas populares, asambleas vecinales.

ABSTRACT: The 19th and 20th December 2001, Argentina lived the most important social protest of its recent democratic history. During the first months of the protest, the irresolution of the institutional re-equilibrium opened the political opportunities for the conformation of a 
new political actor, the assemblies movement, the one that would become a central actor until the institutional re-accommodation with the April 2003 presidential election. Is our goal to study from its origin in all its complexity the novel characteristics that this movement will assume. For this, we will support our study in the ethnographic observation done on the cases of the Asamblea Vecinal de Palermo Viejo and the Asamblea Popular Cid Campeador, from January 2002 to February 2003. These cases can be considered representatives of the two groups that will compose the movement, defining their identity, organizational structure, as well as the repertoires of collective action that we will analyze in this article.

Key words: Argentina, social movements, social protest, popular assemblies, neighbourhood assemblies.

\section{INTRODUCCIÓN}

El 19 y 20 de diciembre de 2001 la Argentina vivió la más profunda crisis institucional desde que la democracia fue restituida en 1983. Este estado de permanente excepción se extiende hasta el 2003 por la irresolución en la relegitimación del rumbo a seguir producido por la asunción del peronista Eduardo Duhalde de la Presidencia interina bajo un pacto de cúpulas entre los principales partidos. Es este contexto el que permitió desde la embrionaria y disruptiva protesta social, la constitución del llamado «movimiento social asambleario». Este novedoso movimiento que marcó el período de reequilibramiento del régimen hasta la elección presidencial de 2003, posee una complejidad muy profunda. Esta complejidad, que excede del mero contexto en el que emerge, se expresará por medio de dos grupos que la distinguirán a través del tiempo. Por un lado, el ala moderada, las llamadas «asambleas vecinales», y, por el otro, su ala radical, las «asambleas populares».

Es por ello que en este trabajo se busca indagar en las razones por las que se conforma la identidad de cada caso, así como presentar y ejemplificar las características típico-ideales de los dos grupos, buscando presentar sucintamente la complejidad del más reciente actor político de la de . ocracia argentina. Para ello -luego de una breve presentación del contexto de emergencia- nos basaremos en el estudio etnográfico realizado desde enero de 2002 hasta febrero de 2003 en dos casos, la Asamblea Vecinal de Palermo Viejo y la Asamblea Popular Cid Campeador (casos representativos de los dos grupos que conformarán al movimiento), para analizar cómo definirán su identidad, estructura de organización y repertorios de acción colectiva. El artículo concluirá caracterizando el contexto de emergencia a fin de responder al interrogante sobre las posibilidades de constitución en un nuevo actor político relevante.

\section{BREVE PRESENTACIÓN DEL CONTEXTO DE EMERGENCIA: DEL SURGIMIENTO DEL PROBLEMA INSOLUBLE AL VACÍO DE PODER}

Fernando de la Rúa asume la Presidencia en el año 1999 gracias a una coalición de gobierno entre su partido, la centenaria Unión Cívica Radical (UCR), y el nuevo 
partido de centro-izquierda Frente País Solidario (FREPASO). Se busca conformar un gobierno de centro con De la Rúa como presidente y el líder del otro partido, Carlos «Chacho» Álvarez, como vicepresidente. Esta coalición es llamada Alianza y los catapulta al poder derrotando al peronista Eduardo Duhalde.

Todo gobierno asume una cuota de legitimidad y un bagaje de promesas que debe cumplir de forma eficiente y eficaz para mantener y -en el mejor de los casos-ampliar la legitimidad. A partir del momento en que va mostrando señales de ineficacia e inefectividad su legitimidad inicial empieza a decrecer'.

La Alianza asume la presidencia bajo una doble promesa. Se presenta como la solución a la grave recesión, empobrecimiento y desempleo, ofreciendo, por un lado, una alternativa de centro a la crisis causada por la década de gobierno del peronista Carlos Menem (1989-1999) y, por el otro, una promesa puramente republicana. Ante el creciente deterioro de las instituciones y la generalizada corrupción, el gobierno de la Alianza surge como una alternativa más transparente y respetuosa de la división de poderes, que buscará reencauzar las instituciones que han sido manipuladas durante la última década.

Los problemas surgen rápidamente: a los pocos meses de asumir el poder, el gobierno reconoce que la crisis socioeconómica es más grave de lo que se creía y se suceden varios ministros de Economía que queman las oportunidades de virar la situación, mientras dan señales de falta de soluciones e inefectividad en su aplicación.

Simultáneamente, el gobierno no sólo no logra una gestión más transparente, sino que muestra los mismos patrones de corrupción anteriores. Durante el año 2000 se hace público un escándalo por pago de sobornos en el Senado Nacional para lograr la aprobación de una controvertida Ley de Reforma Laboral. El duro enfrentamiento que genera entre la UCR y el FREPASO lleva a la división de las élites en el gobierno. Mientras la UCR hace todo lo posible por encubrir la situación, viéndose involucrados ministros nacionales en una red de corrupción, el FREPASO, con el vicepresidente como su principal impulsor, asume en sus propias manos la lucha por la investigación y juzgamiento de quienes han sido sospechosos. Esta puja destruye las relaciones en el interior del gobierno, terminando de quebrar el diálogo que se había visto muy afectadc desde hacía unos meses. Producto de este enfrentamiento, el vicepresidente Álvarez, aerrotado políticamente, decide renunciar a su cargo. En un sistema presidencial, con sus conocidas rigideces, lleva a que estos dos problemas se conviertan en insolubles, y disparen un proceso de crisis ya sin retorno.

Paralelamente, la oposición peronista, no sólo no está dispuesta a dar apoyo a los llamamientos del presidente a un gobierno de unidad nacional, sino que un sector del partido que lidera en el principal distrito, la provincia de Buenos Aires, comienza a comportarse al modo de una oposición semileal, apoyando la desestabilización del gobierno.

El vacío de poder y la total inacción del gobierno lleva a que la oposición semileal inserta en el peronismo impulse la circulación de rumores de devaluación de la moneda

1. J. LINZ (1991: 42-43). 
con una crisis hiperinflacionaria. Mientras, el gobierno toma la decisión de convocar al creador de los patrones económicos que rigen desde 1990, Domingo Cavallo, quien impulsa la radicalización de las medidas neoliberales impopulares, a fin de evitar que los rumores se hicieran realidad. Esto -a principios de diciembre de 2001- lleva a la confiscación de los ahorros buscando evitar que siga creciendo la fuga de capitales (se la llamará «corralito»). Solamente será posible retirar de los bancos una cantidad semanal limitada de dinero. Claramente el gobierno había perdido toda legitimidad. Los rumores crecían y se hablaba de que habría una serie de saqueos a supermercados y comercios en las principales ciudades. Todo parecía indicar que los peores temores de las clases medias urbanas se habían hecho realidad.

El 16 de diciembre de 2001 se realizan los primeros saqueos en los suburbios de las principales ciudades, sucediéndose hasta el día 20. Esta situación de emergencia de los estratos en crisis y -en muchos casos- la negativa de las fuerzas policiales a reprimir y/o realizar arrestos masivos, hacen del vacío de poder un hecho inocultable.

El día 20 por la tarde, De la Rúa decreta el estado de sitio por treinta días en todo el país. Esto genera espontáneamente los «cacerolazos» en la ciudad de Buenos Aires y en algunas de las principales ciudades del resto del país. Por la noche, De la Rúa, en un discurso que dará por televisión, intentará justificar el decreto y convocar a un gobierno de unidad nacional por última vez. Esto provoca que espontáneamente vuelva a expresarse el cacerolazo en rechazo al decreto, primero desde las principales esquinas de la ciudad, para luego ir reuniéndose frente a la Caśa de Gobierno.

Esta protesta inicial que so desarrolla con los cacerolazos de la noche del 19 de diciembre, se enmarca, embrionariamente, en el primero de los procesos colectivos de interpretación, el cual marcará una de las formas bajo las que luego se organizará el movimiento asambleario, el de las asambleas vecinales.

Los procesos colectivos de interpretación o marcos interpretativos son la atribución y construcción social que median entre la oportunidad política y la acción colectiva ${ }^{2}$. El estado de sitio «despertó» el temor al retorno a la trágica experiencia de la última dictadura militar (1976-1983). Es por ello que las oportunidades políticas abiertas en este contexto de debilidad, fragmentación y aparente desgobierno llevan a que la amenaza de la violación de los derechos básicos de la poliarquía (ante una democracia de expectativas decrecientes ${ }^{3}$, donde el último bastión son las libertades cívicas en un marco de democracia delegativa), exponga los peores recuerdos de la generación que padeció el último régimen militar y aquella que descubrió que la democracia institucional puede lograrse sin necesidad de la social. La combinación de confiscación compulsiva de los ahorros (último sostén de una gran proporción de las clases medias empobrecidas y subempleadas) y la declaración del estado de sitio en particular, viola la base mínima para la seguridad y libertad individual. Son estos factores los que impulsan la efervescencia de la noche del 19 al 20 de diciembre (Rossi, 2005).

2. D. MCADAM, J. MCCARTHY y M. ZALD (1999: 26).

3. K. REMMER (1996: 253). 
Una vez presentada la renuncia de Cavallo, en la madrugada del 20 de diciembre, y luego que todos los ministros habían hecho lo mismo a fin de favorecer un acuerdo con el peronismo que permitiera un reequilibrio, la policía comenzó a reprimir a la gente que había llegado a la Plaza de Mayo. Esto disuadió a volver a sus casas al grueso de aquellos que espontáneamente se habían manifestado.

Es en el resto de la noche del 20 de diciembre, y en especial durante gran parte del día, donde aparece un segundo proceso colectivo de interpretación entre los militantes de partidos y agrupaciones políticas.

La represión volvió al mediodía durante una protesta de oficinistas frente a la Casa de Gobierno, y mientras las Madres de Plaza de Mayo realizaban una de sus tradicionales marchas. En la misma plaza se encontraban militantes de diversos partidos trotskistas y leninistas (Partido Obrero, Movimiento al Socialismo, Izquierda Unida) y grupos anarquistas, así como piqueteros (Movimiento de Trabajadores Desocupados). Ante este escenario pleno de militantes de izquierda, la inicial marcha espontánea no seguía desarrollándose. Otro componente se «despertó», y es el de las redes informales de militantes, las cuales interpretaron, bajo sus respectivas ideologías, las condiciones «objetivas» de una situación pre-revolucionaria que debía radicalizarse a fin de lograr la transformación del sistema (en cualquiera de las interpretaciones que convivían en ese momento). Este proceso conexo al del día anterior, impulsa un clásico repertorio de barricadas y enfrentamientos violentos con la policía, que lleva al saldo de 25 muertos y 400 heridos. Por la tarde del mismo día, De la Rúa, ante la negativa del peronismo a ocupar los ministerios vacantes y construir un gobierno de unidad nacional, renuncia, saliendo en helicóptero por el tejado de la Casa Rosada, al igual que Isabel Perón después del golpe de Estado de 1976 (Rossi, 2005).

A partir de allí se sucederán durante diciembre diferentes presidentes peronistas (Puerta, Rodríguez Saá, Camaño) hasta que Eduardo Duhalde, líder del mismo partido, asume interinamente la Presidencia hasta mayo de 2003, cuando se logra reequilibrar el régimen con la elección de Néstor Kirchner como presidente.

\section{El origen: Asamblea Vecinal de Palermo Viejo y Asamblea POPUlaR Cid CAMPEADOR}

1. La Asamblea Popular Cid Campeador surge el 11 de enero de 2002 bajo la convocatoria de afiches anónimos que invitaban a reunirse en la plazoleta del monumento al Cid Campeador en el barrio de Almagro de la ciudad de Buenos Aires. Los afiches decían «organicemos las cacerolas» e instaban a que los vecinos de la zona se reunieran el viernes a las 20.30 horas en la plazoleta, punto neurálgico de cinco avenidas. Las asambleas populares surgen como producto de un proyecto consciente de aprovechamiento de las oportunidades políticas bajo las expectativas de extremar los antagonismos reproduciendo focos de beligerancia en diversos puntos de la ciudad. Un miembro y líder de la asamblea reconoce que el origen es producto de la imitación de otro caso: la Asamblea Popular La Paternal Diego «Nano» Lamagna. Esta asamblea es, en la zona, 
una de las primeras y en su nombre combina tanto el del barrio en el que se encuentra como el de uno de los jóvenes asesinados por la policía en los días del estallido social. Este surgimiento «por imitación» es una característica que impregnará a este caso y que se repite en muchos otros del grupo «popular». Un nexo fuerte habrá desde el origen, cuando activistas de La Paternal envían a algunos de sus miembros para multiplicar la experiencia con el objeto de -como dice un asambleísta-: ... «hacerla más cerca de donde se vive» (agosto 2002). Los asambleístas que a su vez son militantes de partidos de izquierda trotskistas impulsan un modelo por penetración territorial ${ }^{4}$. Es decir, el Cid y el grupo de asambleas que comparten este origen surgen principalmente desde grupos de militantes de Izquierda Unida o de agrupaciones anarquistas (Socialismo Libertario) que buscan desde un centro originario (una sede partidaria o una primera asamblea madre) estimular y dirigir la constitución de agrupaciones similares. Estas mismas redes de militancia que se activan para impulsar la penetración territorial, son las que fomentan la creación de la Asamblea Interbarrial de Parque Centenario, un centro coordinador a nivel de la ciudad de Buenos Aires que las nuclea en un proyecto con aspiraciones nacionales. Tanto el Cid como La Paternal y una serie de asambleas que se encuentran en la zona, tendrán un origen común y siempre mantendrán un diálogo estrecho que las llevará a impulsar acciones conjuntas y aprender de sus experiencias.

La presencia de una institución externa que patrocine el nacimiento de estas asambleas es inorgánica, es decir, no es consecuencia de un mandato de los líderes partidarios, sino que los mismos militantes son los que llevan adelante la creación y multiplicación bajo el modelo del Cid, así como por medio de las redes de militancia (por ejemplo las agrupaciones estudiantiles de la Universidad de Buenos Aires). Es ésta la razón por la que en el caso del Cid vemos cómo La Paternal les presenta la idea de hacer una asamblea (bájo el modelo de base de las que se realizan en los movimientos piqueteros o sindicales de izquierda) y le enseña a sus asistentes el modus operandi.

El modo en que su origen ya extá pautado en la mente de los convocantes se vio en su nexo originario y también ən la velocidad con que en la primera sesión definen que fundarán una asamblea y que la misma será popular. También -nos comenta un asambleísta que no es militante- una persona propuso que la bandera argentina fuera el símbolo (algo muy común en los cacerolazos), lo que se rechazó rotundamente. El mito fortalecedor desde el que surge esta asamblea es internacionalista, no se circunscribe a la ciudad ni a la Argentina. Es por ello que se la llamará «popular» y se eliminará de la denominación la contracción «del», la cual aludiría a la pertenencia a un espacio barrial. Como dice el mismo asambleísta: «El Cid no tiene barrio [...] se buscaba que fuera amplio, no limitándose a lo vecinal...». Y luego agrega a fin de aclarar que la asamblea no es barrial: «El Cid es un lugar de encuentro» (agosto 2002).

El Cid fue creado con un fin organizativo nucleado en torno a un centro que estimulará la organización y constitución de más agrupaciones intermedias que se conformarían como sus átomos soberanos. El Cid, con una velocidad que no veremos en el

\section{A. Panebianco (1990: 10).}


otro caso, en su primera sesión no sólo resuelve cómo se autodefinirá sino que asistirá el domingo a la primera Interbarrial considerándola un elemento legítimo y necesario.

2. La Asamblea Vecinal de Palermo Viejo surge el 17 de enero de 2002, pero hay que remontarse a noviembre de 2001 para encontrar el momento de activación de un grupo de amigos-vecinos.

El 20 de noviembre de 2001 el ex presidente peronista Carlos Menem es liberado del arresto domiciliario por encontrar falta de mérito en la acusación de jefe de una asociación ilícita de tráfico de armamentos. La causa llega muy politizada a la Corte Suprema de Justicia, la cual está conformada por una mayoría de jueces adeptos al ex presidente. El día miércoles 21 del mismo mes, Elisa Carriós y Luis Zamora ${ }^{6}$, los nuevos líderes políticos que comienzan a aparecer en el centro de la escena reclamando transparencia y renovación de élites, convocan a un cacerolazo frente al Parlamento para manifestar el rechazo al dictamen de la Corte Suprema. Después del acto, que no es muy concurrido, el grupo de amigos-vecinos junto con gente de la zona que había asistido deciden volver a reunirse la semana entrante a la misma hora y en el mismo lugar para continuar manifestándose en repudio al dictamen que consideran injusto. Esta nueva convocatoria que se realiza «de boca en boca» en el mismo acto, y al margen de los líderes que habían invitado en esta ocasión, los congrega el 27 de noviembre, siendo 8 personas. Ante el fracaso del nuevo acto, que poseía las características de... «una reunión [para] [...] compartir el disgusto; compartir el desencanto con la política» (noviembre 2002), como comenta una de las fundadoras de Palermo Viejo, este grupo decide volver a reunirse y armar pequeños volantes para difundir lo que están haciendo ahí frente al Congreso a fin de invicar a participar a los transeúntes. En este segundo acto, que tenía el formato de una reunión de discusión, reparten volantes que dicen:

Usted y yo somos iguales, somos ciudadanos que sólo reclamamos a nuestros representantes que cumplan con su deber y nos garanticen una democracia participativa, con independencia de los poderes públicos y que el interés que prime sea el bien común (noviembre 2001).

Vuelven a reunirse el 5 de diciembre ya como «Ciudadanos Autoconvocados Contra el Fallo de la Corte Suprema de Justicia», pero no son más de 11 personas. En esta semana, el día 16 empiezan los primeros saqueos y se suceden los hechos que ya se relataron... Vuelven a reunirse el miércoles 19 de diciembre y como la asambleísta comenta: «Nos agarró el cacerolazo en el Congreso» (noviembre 2002). Mientras ellos estaban reunidos, cientos de personas empiezan a llegar caminando o en bicicleta de las dos importantes avenidas que se cruzan allí. A pesar de no saber bien qué pasaba, deciden igualmente plegarse y comenzar a hacer ruido con los demás.

5. Ex radical, candidata a presidenta por su nuevo partido denominado en el 2003.

6. Figura de izquierda, obtiene una banca de diputado por el reconocimiento a su honestidad y no por afinidad ideológica de los electores. 
Tras la caída del gobierno de De la Rúa, comienzan a reunirse todas las semanas hasta el 16 de enero de 2002. El 11 de enero, la asambleísta comenta que de la recién constituida Asamblea de Plaza de Mayo «Nos invitaron a ir a la Interbarrial como Autoconvocados en el Congreso», además el medio de comunicación alternativo Indymedia difunde que asisten a la Interbarrial, considerándolos una asamblea. Esto, dice ella misma, nunca se les ocurrió hasta verlo en la Interbarrial, y -el 16 de enero«...vino un montón de gente, sin cacerolas, a la espera de algo». Ese algo, reconoce, no sabían qué era, y aclara: «...preguntaban por la Asamblea de Congreso, con la expectativa de crear una» (noviembre 2002). Entonces, decidieron fundar la Asamblea de Autoconvocados de Congreso. Así, se fusiona el previo grupo de amigos-vecinos de Palermo Viejo y los asistentes al acto contra el fallo de la Corte Suprema con uno nuevo, compuesto por militantes de izquierda y mucha gente que vive en la zona.

Este proceso que los lleva, casi sin quererlo, y gracias a una combinación de factores como son: otra asamblea que los invita a la Interbarrial, los medios de difusión de los grupos «antiglobalización» y las redes informales de amistad y vecindad conforman los entornos básicos para la creación de esta asamblea. En oposición al Cid, el surgimiento de Congreso -clave en la posterior creación de Palermo Viejo- será por difusión territorial, es decir, se conforma por generación espontánea, sin una institución externa que le dé origen ${ }^{\top}$.

Este mismo grupo de amigos-vecinos, objetores de conciencia que se han activado, fundan -sin experiencia previa en la política- una asamblea fuera del barrio donde viven. Otro de los fundadore: nos comenta que a medida que el pequeño grupo inicial comienza a ampliarse, va cambiando el origen, escaseando los que asistían a la convocatoria inicial, comenzando a participar vecinos del barrio que circunstancialmente transitaban por allí. Una vez pasado el 19 y 7.0 de diciembre, las inquietudes que comienzan a debatirse traspasan la temática del fallo sobre Menem y se acercan a problemáticas del barrio y se añaden temas como el «corralito», la renovación total de las élites, entre otros. A partir de este momento, y gracias al efecto ejemplificador de la Interbarrial, deciden fundar en su barrio una asamblea. En Congreso, la asamblea seguirá su curso ya sin su participación.

Este mismo efecto de generación espontánea que experimentan es el que deciden replicar en el barrio, y -para el 17 de enero- convocan para la primera sesión de la Asamblea de Vecinos Autoconvocados de Palermo Viejo, en la esquina de la casa de uno de los fundadores, en la ciudad de Buenos Aires. En la convocatoria, bajo los reclamos republicanos que surgen en los actos del Congreso, se invita con volantes que distribuyen bajo la consigna: «De nosotros depende el cambio, no dejemos pasar la oportunidad» (enero 2002). Este tipo de asamblea surge bajo marcos interpretativos completamente diferentes a los de las populares, enmarcando las oportunidades de diciembre-enero como una transferencia vertical de la fuente de soberanía a sus orígenes y -ante la abdicación y/o incapacidad de los representantes- emerge la imprescindible necesidad de debatir cómo salvar la República, renovándola en el «retorno» a sus

\section{A. Panebianco (1990: 110).}


principios que han sido corrompidos. Es ésta la oportunidad que no debe ni puede dejarse pasar, y como dice el mismo primer volante:

La Asamblea Vecinal es una forma legítima de participación democrática, sin dirigentes ni partidos políticos, compuestas por ciudadanos en un mismo plano de igualdad con posibilidades de opinar, escuchar y votar para tomar decisiones de interés común. Cada Asamblea trata temas que atañen desde su problemática barrial hasta los de interés nacional (enero 2002).

La asamblea no es la organización de la protesta en focos de beligerancia que impulsen una coordinación central hacia la radicalización creciente del conflicto en un intelectual colectivo ${ }^{8}$ como es concebido el Cid, sino que es una instancia colectiva de decisiones libres para recuperar la República con la renovación total de las élites, las cuales parecen mostrarse torpes y corruptas. Es una oportunidad abierta y que debe tomarse para que -por primera vez en algunos casos, como para sus fundadores- después de años de objetores de conciencia, manifiesten su descontento. Pero una vez que la convocatoria se ha abierto, serán las comunidades de memoria quienes constituyan el componente central en Palermo Viejo (equivalente a la de los militantes de izquierda para el Cid): redes de activistas desmovilizados que en la década de 1970 militaron como estudiantes o en agrupaciones políticas hasta que el régimen militar los llevó a involuntarios objetores de conciencia. A partir de la primera asamblea se iniciará un extenso debate sobre qué so. y qué quieren para la República, nada está definido previamente como en Cid, sólo saben que algo tienen que hacer.

A medida que pasan las sesiones en los dos casos, y en particular debido a las discusiones que ambos grupos enfrentan en la Interbarrial sobre la necesidad de radicalizar la protesta en favor de la instauración de un nuevo sistema diferente al capitalista y la democracia representativa; o redireccionar los objetivos hacia lo local, donde el gobierno de la Ciudad de Buenos Aires se muestra dispuesto a considerarlas interlocutores válidos (enfrentado a una realidad que asciende en momentos a 113 asambleas como puede verse en el Gráfico I), se va produciendo un proceso de paulatino filtrado de miembros, consolidándose su tendencia de origen -moderada o radical-para principios de abril de 2002, momento en que se consolida la división del movimiento social en dos grupos.

8. En un modelo que podríamos llamar «gramsciano», donde las clases trabajadoras dialoguen con los nuevos sectores que se han politizado: las clases medias urbanas, en pos de la consecución de una nueva forma de organización socioeconómica. 


\section{GRÁFICO I}

Evolución mensual de asambleas en la ciudad de Buenos Aires (2002)

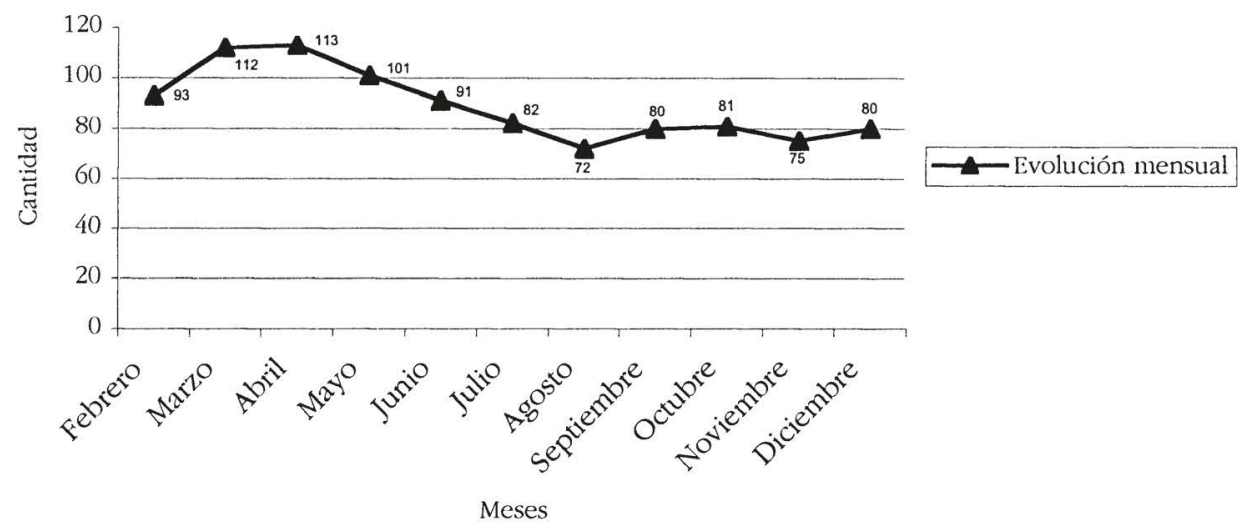

Fuente: http://www.todosjuntos.foros.org (consultada durante 2002); http://www.elcacerolazo.org (consultada durante 2002); Centro de Estudios para la Nueva Mayoría (marzo 2002), Periódico 19 y 20 n. ${ }^{\circ} 0$ y n. ${ }^{\circ} 1$ (Buenos Aires); http://www.ar.geocities.com/apbnweb/APBN1.htm (consultada durante 2002 y 2003); http://www.palermoviejo.netfirms.com (consultada durante 2002 y 2003).

\section{IDENTIDAD: «REDEFINICIÓN DEL MUNDO SOCIAL EN TIEMPOS DE CAMBIO»"}

La Argentina, desde al menos principios de la década de 1990, sufre un proceso de creciente disolución de los referentes de certidumbre que han caracterizado a las relaciones sociolaborales y políticas en el último medio siglo. La reducción del Estado en sus papeles no coactivos ha desintegrado los principios organizadores de la solidaridad $^{10}$. La desinstitucionalización de los marcos colectivos que estructuraban la identidad social e individual no es sólo producto del retroceso del Estado en sus papeles sociales, sino también de lo que Beck (1994) llama modernidad reflexiva. Es decir, una de las transformaciones sistémicas que sufre la sociedad industrial es la paulatina disolución de sus bases constitutivas; se consumen y disuelven en el reconocimiento de la impredecibilidad de las amenazas provocadas por la misma modernización de la modernidad. La consecuente compulsiva individualización hace de la identidad un proyecto reflexivo y autónomo a construir.

Pero, como dice Castel (1997), en un contexto donde el individuo se encuentra fragilizado por la disolución de las pertenencias colectivas que organizaban su vida y la

9. Esta frase pertenece al excelente artículo: G. KESSLER. Redefinición del mundo social en tiempos de cambio. Una tipología para la experiencia de empobrecimientos. En M. SVAMPA (2000: 25-50).

10. P. Rosanvallon (1995: 10). 
vulnerabilidad por la pérdida de muchos de sus recursos materiales y simbólicos, vive las exigencias de autonomía individual en términos de los riesgos «...de la exclusión no sólo social, sino también institucional y simbólica.... ${ }^{11}$.

Es decir, la falta de resguardos materiales y simbólicos dificulta las posibilidades de la emancipadora constitución identitaria, padeciéndose una situación de vulnerabilidad y caída social, viviendo la exigencia de individualización en términos de anomia y fragilización. Si a ello se le suma un contexto de desocupación masiva y crecimiento de la exclusión, el Estado en su funcionamiento bajo la concepción tradicional de derechos sociales deviene inadaptado e incapaz de dar respuesta a situaciones que ya no son coyunturales ${ }^{12}$. En resumen, ante el nuevo contexto de vulnerabilidad y caída social y un Estado incapaz de responder, los individuos se ven obligados a redefinir el mundo en el que viven a fin de poder relacionarse de alguna nueva manera con él.

En el marco de este proceso, una crisis de la magnitud de la acaecida en diciembre de 2001 lleva a la movilización y activación política, pero la crisis con la que se enfrentan las autoridades no es la de una puja entre élites, sino que se enmarca en la crisis de la democracia de partidos donde las comunidades de partido ya no otorgan a los miembros una pertenencia que ellos reconozcan. Es decir, la disolución de las comunidades de vida peronista y radical, la imposibilidad del FREPASO para constituir una nueva, y el mantenimiento de la rígida disciplina partidaria en un contexto će creciente reflexividad y heteroformismo social, 'ileva a una quiebra donde implosionan los canales conductores de la representatividad y la accountability vertical. En caso contrario, en una crisis de esta magnitud en el mar co de firmes identidades partidarias, simplemente hubiese acaecido un turbulento reacomodamiento y realineamiento de élites en el traspaso del poder del radicalismo al peronismo hegemónico. Más allá de existir este juego estratégico, no es el que da forma y explica al movimiento asambleario.

Ante este contexto, partiendo de un origen catártico, las asambleas se constituyen como elementos mediadores que permiten en un ámbito de mutua contención la construcción de nuevos referentes que den certidumbre (una explicación de lo que sucede y un nuevo lugar en este mundo de la vida) y contengan simbólicamente a sus miembros ante la fragilización y caída social.

Una forma de ilustrar anecdóticamente esta afirmación, la encontramos en una situación vivida por una asambleísta de Palermo Viejo. Su perro se pierde, y gran cantidad de miembros organizan cuadrillas para encontrarlo en el barrio. Una vez que lo encuentran, la miembro agradece por correo electrónico diciendo: «...desde que funcionan las asambleas no me siento tan sola como antes $»^{13}$. Se ve la relación de afecto y solidaridad que el origen catártico produce entre sus miembros tanto en esta anécdota como en lo que expresa otra asambleísta cuando se le pregunta: ¿cómo eran las primeras asambleas?: «Eran como un lugar de expresión. Cada uno contaba qué le preocupaba y todo lo que vivíamos...» (noviembre 2002). Es decir, ambos casos parten de dos marcos

11. M. SVAMPA (2000: 117).

12. P. RosanVALLON (1995: 10-11).

13. Citado por A. LE FUR (2002: 36). 


\section{6 \\ FEDERICO MATÍAS ROSSI \\ CRISIS DE LA REPÚBLICA DELEGATIVA. LA CONSTITUCIÓN DE NUEVOS ACTORES \\ POLÍTICOS EN LA ARGENTINA (2001-2003): LAS ASAMBLEAS VECINALES Y POPULARES}

interpretativos y orígenes diferentes, pero los dos deben buscar la forma de constituir una identidad que establezca lazos de solidaridad en los que los años de objetores de conciencia, así como la fragilización y caída social, puedan ser explicados y resignificados. El fin de la soledad en el padecimiento de la pauperización y la sensación de que es una condición compartida permiten a sus miembros partir de una «integración catártica» que luego irá deviniendo en una base identitaria, pero nunca se perderá lo que un asambleísta dirá un año más tarde durante una sesión: «Acá nos reunimos por afecto... hay una cuestión política... pero nos reunimos por afecto» (diciembre 2002).

Cada caso llevará adelante de diferente manera esta construcción de contención. Es decir, los dos casos se inscribirán socialmente basándose en marcos interpretativos radicalmente diferentes, y esto constituirá ambos tipos de identidad. A su vez, la inscripción social de las dos asambleas será bidimensional. Por un lado, se inscribirán «identitariamente», aludiendo con ello a la redefinición del mundo de la vida y su relación en el nuevo contexto; y por otro lado -simultáneamente- se inscribirán «políticamente», refiriéndonos con ello a la inscripción social estratégica que buscarán constituir a fin de conformarse como un nuevo interlocutor válido en el mundo político.

\section{LAS CARACTERÍSTICAS DISTINTIVAS DE CADA GRUPO ${ }^{14}$}

Se podría reformular el título y decir: ¿qué significa que una Asamblea sea «popular» y que otra sea «vecinal»? Producto de la doble inscripción que simultáneamente cada caso lleva adelante, es posible formular las características de las asambleas populares y las vecinales, a fin de comprender la gran complejidad que existe en el movimiento.

1. Típico idealmente, las asambleas populares parten de la concepción del contexto de apertura de las oportunidades políticas de diciembre de 2001 como la evidencia de la crisis del sistema capitalista o del modelo neoliberal y de la democracia representativa de partidos. Es por ello que es imprescindible organizar diversos focos de beligerancia popular en un diálogo entre clases sociales bajo el modelo del intelectual colectivo multiclasista gramsciano. El sentido de esto se deposita en el poder soberano (supremo y originario) y disruptivo con potencial constituyente de un nuevo ordenamiento que se expresa en los cacerolazos y que sintetizan bajo la idea del «espíritu de la asamblea». Para lograr esto, el diálogo interclases es imperativo. Los consensos paulatinos del metacolectivo indivisible «pueblo» que representan buscan construir un nuevo poder opuesto al actual bajo el principio rector de «unidad de todos los sectores en lucha». En este sentido, es ilustrativa la siguiente cita:

...objetivo primordial: la construcción de una red de contrapoder capaz de democratizar los espacios de gestión desde abajo. Es entonces necesario pensar que la lucha por el poder no pasa solamente por la política como la conocemos, sino por las prácticas que

14. Agradezco a Javier Auyero por los comentarios a una versión previa de este apartado. 
producen nuevos valores y experiencias de una sociabilidad no hegemonizada por el capitalismo. [Convocatoria Contra-Electoral, reacción de un asambleísta en Indymedia, 27 de enero de 2003].

Con este fin típico se impulsarán acciones colectivas beligerantes que desafíen los principios básicos del sistema que se rechaza. Por ejemplo, el Cid, al comenzar el invierno, decide obtener un lugar para sesionar. Una vez pasados unos meses en el ball de entrada del Club Social y Sportivo Buenos Aires, deciden ocupar ilegalmente una sucursal abandonada de un banco, donde se instala La Casa del Cid Campeador. La estrategia de obtención del lugar-«aprendida» de la experiencia de la Asamblea Popular Villa Crespo «Gustavo Benedetto» y de la Asamblea Popular Lezama Sur- se enmarca en la búsqueda de violar abiertamente la propiedad privada y desafiar al poder económico-financiero en particular, considerado uno de los impulsores del sistema y modelo que se rechaza. En un volante que distribuyen una vez que han ocupado el edificio se sintetiza la interpretación de la obtención del lugar como un hito en la «lucha contra el sistema»:

En donde antes funcionó una institución financiera que estafó a miles de ahorristas y dejó en la calle a cientos de trabajadores (un Banco Mayo), hoy la Asamblea conquistó un espacio abierto para todos... (oct'ibre 2002).

En el Boletín Asamblea Fotular Cid Campeador ( . $^{\circ} 7$, año 1, del 8 de agosto de 2002) dicen: «El domingo 28 de julio la Asamblea Popular Cid Campeador recuperó para el pueblo el local del ex Banco Mayo...». Es importante notar que la «recuperación» es de un espacio «para el pueblo», y se enmarca en que «Desde el 19 y 20 de diciembre, los argentinos recuperamos nuestra capacidad de lucha y resistencia...» (septiembre 2002), siendo el edificio un centro político-contracultural estratégico para la multiplicación de referentes y focos organizadores de la protesta social. Como dicen en el mismo boletín: «Se discute que el local sirva para organizar y coordinar las luchas y reivindicaciones de los trabajadores de la zona».

A su vez, el criterio que unificará al movimiento y a las redes de aliados será la existencia de un enemigo común al que se combate al compartirse la condición de víctimas o excluidos. Esto se observa en la relación que las asambleas populares establecen con la fábrica recuperada «bajo control de los trabajadores» Brukman. La misma es apoyada más allá de no encontrarse en la zona y por ser parte de una construcción alternativa al modo de producción que rechazan, donde se busca la autogestión obrera de la empresa bajo propiedad estatal. Es decir, los une el enemigo común, rigiéndose bajo el principio de unidad de sectores en lucha.

Por lo tanto, el tipo-ideal «popular» define al principio que rige a los cacerolazos, «que se vayan todos, que no quede ni uno solo!», como la construcción de una forma alternativa al sistema capitalista o al modelo neoliberal y a la democracia representativa de partidos. En cambio, lo que se busca es el autogobierno, como dijo un asambleísta: «La alternativa existe, es genuina, el gobierno de nosotros, los excluidos 


\section{8 \\ FEDERICO MATÍAS ROSSI \\ CRISIS DE LA REPÚBLICA DELEGATIVA. LA CONSTITUCIÓN DE NUEVOS ACTORES \\ POLÍTICOS EN LA ARGENTINA (2001-2003): LAS ASAMBLEAS VECINALES Y POPULARES}

y los oprimidos»; y como aclara otro en la misma sesión: «...lo que rechazamos es que votar no es decidir, porque decidir es deliberar pública y colectivamente en asamblea soberana» (enero 2003). En este sentido, no hay límite a la extensión del «ique se vayan todos...!», abarcando por igual el autogobierno a nivel ciudad de Buenos Aires como en el espacio nacional y, por tanto, impugnándose al Estado como tal.

Es en este marco que el sentido dado a toda acción «solidaria» (comedor comunitario, cursos y talleres gratuitos, entre otros) es el de una herramienta estratégica en la construcción de un movimiento popular, siendo las primordiales aquellas consideradas «políticas», es decir, las que se dirigen a la acción contenciosa o la reflexión a fin de obtener consensos en la construcción de un nuevo poder.

Durante gran parte del año 2002, las asambleas populares, como el Cid, establecen su relación con las demás asambleas de la ciudad de Buenos Aires por medio de la Asamblea Interbarrial de Parque Centenario, así como a través de sus reuniones temáticas (Intersalud, Intertomas, Interprivatizadas, principalmente). Esta asamblea de carácter especial es un ente coordinador de asambleas con el objeto de unificar líneas de acción e impulsar la construcción de un «movimiento asambleario» en estrecho parentesco con grupos de pertenencia política, o al menos bastante influenciado por éstos.

Esta asamblea como ente coordinador a nivel de la ciudad de Buenos Aires y alrededores se encuentra sometida a la voluntad de sus átomos constitutivos: cada asamblea como instancia de autoridad máxima (consideradas soberanas).

A su vez, hasta marzo de $\rightarrow 002$ existe, organizada bajo iniciativa de la Interbarrial la Interasamblea Nacional o Azamblea Nacional de Asambleas Populares, que nuclea a las asambleas como coordinadora del espectro nacional, también sometida a sus átomos constitutivos. Las relaciones y jerarquías de este modelo organizativo se encuentran resumidas en el Gráfico II.

2. Por su parte, las asambleas vecinales parten de la concepción del contexto de apertura de las oportunidades políticas de diciembre de 2001 como la evidencia de que la experiencia de transformaciones vividas desde al menos principios de la década de 1990, se basa en el hecho de haber delegado permanentemente el poder de decisión en los representantes de un sistema político que no posee canales de accountability vertical eficaces y un tipo de institucionalización particularista donde la participación ciudadana está prohibida o muy restringida.

Es por ello que es imprescindible organizarse para responder(se) qué se busca para la República, cómo se lo busca (y de qué forma se lo debe buscar). El diálogo entre los miembros y la percepción de que esto se debió a un proceso de fragilización y caída social en una creciente individualización de lo social explica el motivo de la continuidad de su existencia en la búsqueda de la generación y la reconstrucción de lazos sociales en una organización comunal por medio de un movimiento urbano como Castells (1997) lo define:

...movimientos urbanos (procesos de propositiva movilización social, organizados en un territorio dado, orientados hacia objetivos relacionados a lo urbano) donde se enfocan tres principales conjuntos de objetivos: demandas urbanas sobre condiciones de vida 
GRÁFICO II

ASAmblea Popular Cid CAMPEADOR: MODELO ORGANIZATIVO

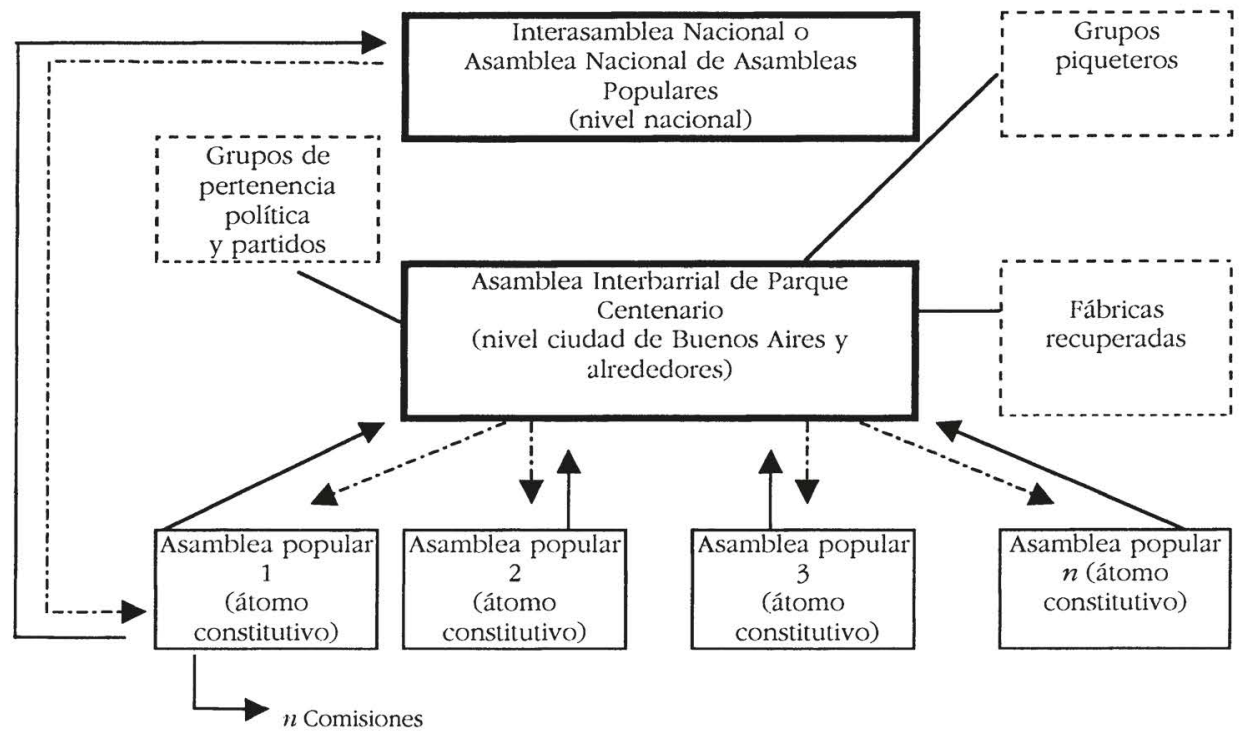

$\rightarrow$ Relación jerárquica (fuentè de mandato).

- Sin relación jerárquica.

4-- Circuito de resoluciones para su refrenda (devolución del mandato).

$\square$ Entes coordinadores.

Instancia máxima.

. Grupos que participan informalmente (sin derecho a voto).

Fuente: Elaborado a partir de la observación etnográfica de enero de 2002 a febrero de 2003.

y consumo colectivo [reducción de tarifas de TV por cable, evitar aumento de los servicios públicos]; la afirmación de una identidad cultural local [vecinos]; y la conquista de la autonomía política y la participación ciudadana [ley de Comunas] ${ }^{15}$.

En esta dirección es ilustrativo el motivo con el que se provee de sentido en el caso de Palermo Viejo al festival «La Trama» (organizado para conmemorar la Revolución de Mayo de 1810) expresado por una fundadora:

La Trama a mí me sirvió para darme cuenta un poco del por qué y cuál era el norte de la asamblea, cuáles debían ser sus objetivos: esto de vincularnos con el barrio y articular

15. M. CASTELLS (1997: 60, traducción del autor). 
FEDERICO MATÍAS ROSSI

CRISIS DE LA REPÚBLICA DELEGATIVA. LA CONSTITUCIÓN DE NUEVOS ACTORES

POLÍTICOS EN LA ARGENTINA (2001-2003): LAS ASAMBLEAS VECINALES Y POPULARES

distintos actores en el barrio y a los vecinos. Aparte de que demostramos que éramos capaces de hacer un proyecto autogestionado (enero 2003).

También puede verse en la forma en que explican el motivo por el que desean un espacio donde funcionar y solicitan en comodato un mercado comunitario abandonado al Gobierno de la Ciudad de Buenos Aires ${ }^{16}$ :

La iniciativa surgió a partir de la necesidad de tener un lugar común donde encontrarnos para desarrollar distintos proyectos y disponer de un medio para promover la articulación de los distintos sectores del barrio (octubre 2002).

Es importante notar que la recuperación de un espacio es «para el barrio» y tiene la finalidad de emprender un centro cultural barrial y promotor de microemprendimientos entre los vecinos del «lugar».

A su vez, el criterio que unificará al movimiento y las redes de aliados será la pertenencia o cercanía al ámbito de influencia (entendido como el espacio de cohabitación resignificado como un «lugar», buscando hacer del barrio una fuente de identidad, relaciones e historia ${ }^{17}$. Esto se observa en la relación que las asambleas vecinales de la zona establecen con la fábrica «recuperada bajo control de los trabajadores» Grissinopoli. En este caso, el vínculo con una fábrica en esta condición no se da por participar de algún proyecto que cuestione o presente una alțernativa al sistema, sino por ser parte de la trama que integia el lugar de cohabitación del que forman parte. Como movimiento urbano, buscan favorece" el logro de sus objetivos espacialmente delimitados en una comunidad entendida «...no sólo [como] los vecinos del barrio sino también $[. .$.$] los comercios, pequeñas industrias y talleres que en ella conviven...» (octubre$ 2002). En otras palabras, las asambleas vecinales buscan crear relaciones de afirmación y sociabilidad sociocultural bajo una inscripción identitaria territorial.

Por lo tanto, el tipo-ideal «vecinal» define al «ique se vayan todos...!» como la construcción de otra forma de gestión de lo político y la renovación de las élites en el poder por medio de: «Evaluar la posibilidad de convocar a elecciones para legitimar a nuestros representantes» (enero 2002). El sentido de este fin se expresa en la concepción de la necesidad de una creciente participación en la gestión de gobierno, como dice un asambleísta en una sesión en enero de 2003: «Este sistema de representación en el que vos vas votas y si no te gusta, dos años más tarde vas y votas a otro, es el que está en crisis [...]. El 19 y 20 fue el principio del fin de este sistema de representación». No se rechaza el sistema representativo de la democracia de partidos, sino que se busca una mejora en los canales de participación ciudadana, así como

16. El proceso hasta la decisión de obtener el mercado es extenso y parte de la necesidad de un espacio ante el invierno y las lluvias, así como un lugar donde funcionar permanentemente. Primero se utiliza un garaje de la zona; durante un mes un restaurante llamado «Acá Bar» les presta un salón, hasta que el Club Atlético Palermo les autoriza a sesionar en su espacio.

17. M. Augé (1994: 147). 
la generación de mayores y mejores vías de accountability vertical. También, entienden el «ique se vayan todos...!» como la renovación de las élites en el poder que han gobernado durante los años de democracia desde 1983 y la construcción de lo que llaman «otra» política:

La sociedad argentina no lo necesita porque ya está pensando en una nueva construcción política, con una justicia eficiente que destierre la impunidad, un sistema político que concrete la participación de los ciudadanos en las acciones de gobierno, y un sistema económico capaz de brindar oportunidades a todos los sectores (carta «Menem, ¡ya basta!», enviada en junio de 2002 al programa televisivo Hora Clave en rechazo a la presentación del ex presidente Carlos Menem, destacado en el original).

En el ámbito local, entienden a esta otra política como la sanción de la ley de Comunas, lo que implicaría la descentralización en distritos de la ciudad de Buenos Aires, y la generación de ámbitos barriales de participación directa. En resumen, definen al gobierno nacional como adversario por considerarlo no representativo. En ese sentido, la crítica implica tanto al gobierno de De la Rúa, por haber traicionado el mandato, como al de Duhalde por haber alcanzado la Presidencia sin el voto ciudadano. A diferencia del tipo popular, consideran al Estado como un conjunto de instituciones propias, pero con un gobierno carente de legitimidad. De este modo, el gobierno de la Ciudad de Buenos Aires se convierte en un interlocutor válido ya que ha sido elegido por el voto ciudadano, y es po: ssta razón que interactúan con él por medio de sus centros de gestión y participación (oficinas de descentralización administrativa de la gestión de gobierno).

Es en este marco que el sentido dado a toda «acción solidaria» (feria de artesanos, campañas de recolección de alimentos, microemprendimientos productivos) no es excluyente de su definición simultánea como «política», en el sentido del fin establecido de generación de canales de reconstrucción de lazos sociales y de impulso de la participación en la gestión de la política local.

Palermo Viejo, al igual que parte importante de las asambleas vecinales que habían tenido algún vínculo con la Interbarrial, después de un período inicial de relación estrecha (hasta marzo de 2002, bajo el modelo de las asambleas populares expresado en el Gráfico II) dejan de enviar delegados a la Interbarrial, para concentrarse en las relaciones locales a través de la Mesa de Enlace o Asamblea Interzonal Viaducto Carranza (en el caso de Palermo Viejo, existiendo equivalentes en otras zonas), donde se vinculan con las asambleas de la zona norte de la ciudad de Buenos Aires en un ente de coordinación barrial.

Este tipo de coordinación no extrae resoluciones, sino que es un ámbito donde los delegados de las asambleas comparten las iniciativas que están impulsando y buscan llevar adelante algunas en conjunto. Este tipo de coordinación no excluye la relación independiente y directa entre asambleas más allá de la Interzonal. El Gráfico III resume las relaciones y jerarquías de este modelo organizativo. 


\section{2}

FEDERICO MATÍAS ROSSI

CRISIS DE LA REPÚBLICA DELEGATIVA. LA CONSTITUCIÓN DE NUEVOS ACTORES

POLÍTTCOS EN LA ARGENTINA (2001-2003): LAS ASAMBLEAS VECINALES Y POPULARES

\section{GRÁFICO III}

Asamblea Vecinal de Palermo Viejo: modelo organizativo

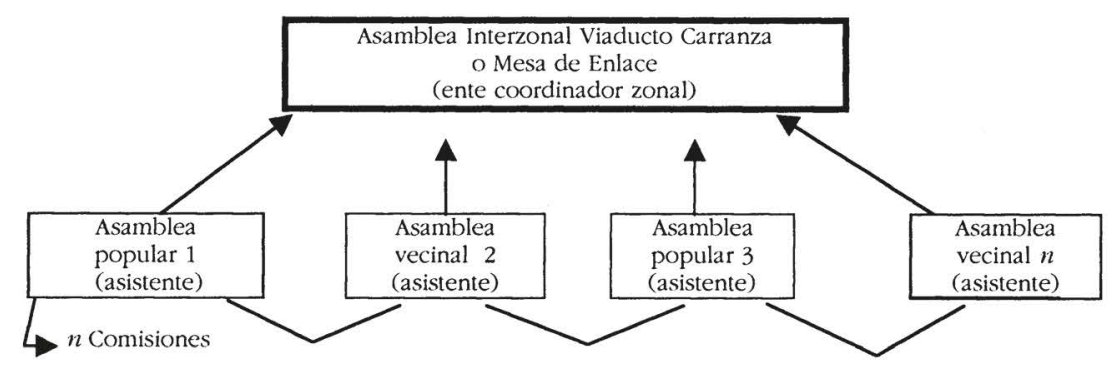

$\rightarrow$ Relación jerárquica (fuente de mandato).

Sin relación jerárquica (vínculos).

Ente coordinador.

Instancia máxima.

Fuente: Elaborado a partir de la observación etnográfica de enero de 2002 a febrero de 2003.

\section{A MODO DE CONCLUSIÓN: ¿SE HAN CONSTITUIDO COMO UN NUEVO ACTOR POLÍTICO RELEVANTE? ${ }^{18}$}

No puede atribuirse a los conizxtos estructurales la generación de las explosiones de acción colectiva. Estas condiciones constantes no se pueden consideradar causa del surgimiento de los movimientos sociales. Las causas son aquellas variaciones coyunturales del contexto de emergencia. Por ello, para responder qué identidad han constituido y cómo se organizan es imprescindible responderse cómo y por qué surgieron ${ }^{19}$. Resulta entonces interesante concluir este artículo con el siguiente apartado a fin de comprender por qué no se convirtió en un actor político relevante el movimiento que hemos presentado típico-idealmente en su ala moderada (vecinales) y ala radical (populares). Para ello es importante preguntarse cómo definir lo que sucedió en las jornadas que moldearon al movimiento social, o en forma de pregunta: «¿es posible ver en las jornadas del 16 al 30 de diciembre en la ciudad de Buenos Aires un estallido social?».

Farinetti (1999) define al «estallido social» como un tipo histórico de protesta donde se dan una serie de rasgos comunes: los actores son generalmente los empleados del sector público (provincial y municipal) apoyados por amplios sectores de la población; las demandas se sintetizan en la defensa del salario y el empleo, generando el desencadenamiento el atraso en los pagos. Su modo de expresión es la concentración en las

18. Agradecemos a Leonardo Morlino por las sugerencias que fundaron esta conclusión.

19. S. TARROW (1997: 49). 
calles y la movilización, junto con actos de violencia hacia los símbolos de la vida política, como son los incendios a edificios públicos y ataques y saqueos a domicilios de políticos. El alcance de la protesta está espacialmente delimitado (se circunscribe a la capital y principales ciudades del Estado provincial) y es episódico, no derivando en algún movimiento social con objetivos propios. El destinatario es el gobierno local y su clase política, generando un alto impacto y una gran crisis que deriva en la renuncia del gobernador e intervenciones federales. El lenguaje de la protesta es contra el poder local, es moral (se alzan contra la corrupción y la descomposición moral de la vida política, reclamando su «purificación») y es personalizada, al atacarse directamente a funcionarios y dirigentes políticos (mostrando la personalización de la política).

Dicho esto, es notable ver cómo las similitudes entre esta definición utilizada para explicar los estallidos de beligerancia popular a escala local y las particularidades de la crisis de diciembre de 2001 nos permiten compararlos. Se encuentran las siguientes similitudes: los actores primordiales que desencadenan la crisis (que se inicia mucho antes de diciembre) son los empleados públicos que ven reducido un $13 \%$ su salario, a los cuales luego se le agrega el apoyo del resto de la población. La paralización en el cobro de los salarios alcanza a toda la población con la sanción del «corralito» (donde no podían ser retirados en cuotas de más de un cuarto por semana). La demanda inicial (es decir, durante el gobierno de De la Rúa) es en rechazo a los reiterados ajustes y el aumento de impuestos, así como a la reiteración de las formas políticas del gobierno de Menem (la doble promesa económica-republicana, truncada por la Alianza). Su modo de expresión es la movilización y concentración callejera (en todas las principales esquinas) y hay ataques a edificios públicos simbólicos (se incendia parte del Congreso Nacional, se atacan las vallas de seguridad de la Casa de Gobierno, se incendia y saquea el comité central de la UCR, entre otros). También se ataca directamente a políticos y sus propiedades (las casas de los jueces de la Corte Suprema de Justicia son las más agredidas, aunque nunca sucede algún saqueo). Se dan con particular virulencia reiterados «escraches» y expulsión de lugares públicos a funcionarios políticos de cualquier extracción que hayan ocupado algún cargo en los últimos 30 años (jueces de la Corte, ex ministros de Economía, del Interior, legisladores nacionales, el ex presidente Raúl Alfonsín, entre otros). Su impacto es también una importante crisis política, llevando a renuncias de funcionarios y vacío de poder hasta la intervención por otra instancia (la Asamblea Legislativa). Otra importante similitud es el lenguaje moral de los manifestantes, el reclamo de «ique se vayan todos, que no quede ni uno solo!» se sustenta en principios de renovación basados en la impugnación moral de sus integrantes. Esto es sintetizado en frases como: «Nadie votó a Menem, Grosso ${ }^{20}$, Manzano $^{21}$, Daer y Moyano ${ }^{22}$, ique se vayan todos!» o «Pasamos Nochebuena, pasamos Navidad, echamos a De la Rúa y ahora a

20. Primer político juzgado por corrupción, símbolo de la década menemista, luego integró la semana de gobierno interino de Rodríguez Saá en diciembre de 2001.

21. Mano derecha de Menem durante su gobierno y ministro del Interior durante parte de él.

22. Ambos, desacreditados líderes del sindicalismo peronista de la Confederación General del Trabajo (CGT). 
los demás». El reclamo de «ique se vayan todos...!» es posible interpretarlo (más allá de lo dicho para los tipos-ideales vecinal y popular) como la expresión de la exigencia de la «purificación» de la política ante la impugnación moral de sus integrantes.

En cambio, hay una serie de diferencias, principalmente debido a que su alcance parece no ser localizado. No lo es porque implica una revuelta no contra el gobierno de la ciudad (quien sale airoso de la crisis), sino contra el nacional. Pero su alcance (más allá de haber generado un efecto dominó desencadenando estallidos en otras provincias y cientos de municipios produciendo varias renuncias o remociones) se concentra en la ciudad de Buenos Aires y sus suburbios. Por lo que es localizado en la capital nacional, lo que implica que sea nacional su impacto ya que su destinataria es la autoridad presidencial. Otra diferencia es que no es episódico, ya que se forman al menos dos movimientos sociales, el de los ahorristas (que concluye con su objetivo de reintegración de los ahorros) y el asambleario. Pero no es episódico simplemente porque la irresolución del conflicto se extiende durante un año desde el interregno de Duhalde hasta la convocatoria a nuevas elecciones presidenciales. El «congelamiento» de la resolución de ciertas reclamaciones impulsa la desistitucionalización de la puja y lleva a la organización del movimiento social.

Por lo tanto, lo que parece haber sucedido es una «pueblada» en la capital de la nación, federalizando su alcance produciendo un efecto contagio en el resto del país. Es decir, la crisis de diciembre de 2001 es un estallido social dirigido a las autoridades nacionales que genera -producto del interregno de Duhalde- un impasse particular que debido a su irresolución a'bre la puerta a la constitución de una forma organizativa e identitaria de emergencia. Es por esta misma razón que el movimiento asambleario no se ha constituido en un actor relevante de la política argentina, $y$ ha perdido su relevancia en la local. El movimiento solamente pudo justificar la continuidad de su existencia en la impugnación del gobierno interino de Duhalde y en su reclamación de renovación radical. Una vez cerradas las oportunidades políticas nacionales y virados o radicalizados los objetivos, sólo mantienen su tibia existencia producto de la irresolución de las elecciones nacionales, de la ciudad y la renovación parlamentaria y de algunos jueces de la Corte Suprema. Hasta que no se plebiscita con la elección presidencial del 27 de abril de 2003 el rumbo abierto a partir del 19 y 20, la puja se desarrolló extrainstitucionalmente. Una vez renovados los cargos en estos espacios, el movimiento se concentrará -como se vio- en lo local o simplemente se apagará. Sin negar el impacto político irreversible que el estallido y el movimiento tuvieron sobre la política argentina (del cual aún no se han expresado todas sus consecuencias); es apropiado ver en lo sucedido un estallido social extendido en el tiempo por la demora en lograr una resolución plebiscitaria sobre el rumbo a seguir, dando sentido y motor durante su corta existencia a la organización del movimiento social asambleario en dos grupos caracterizados típico-idealmente como aquí se ha hecho. Una vez reacomodado el sistema político, el movimiento se comenzará a apagar lentamente... 
VII. BIBLIOGRAFÍA

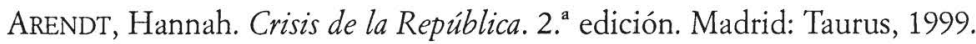

Augé, Marc. Hacia una antropología de los nuevos mundos. 1. edición. Barcelona: Gedisa, 1994.

Auyero, Javier. La Protesta. Retratos de la beligerancia popular en la Argentina democrática. 1. ${ }^{a}$ edición. Buenos Aires: Centro Cultural Ricardo Rojas, Universidad de Buenos Aires, 2002.

- Los cambios en el repertorio de la protesta social en la Argentina. Desarrollo Económico, 2002, vol. 42, n. ${ }^{\circ} 166$, pp. 187-210.

BECK, Ulrich. The Reinvention of Politics: Towards a Theory of Reflexive Modernization. En BECK, Ulrich; GIDDEns, Anthony y LASH, Scott. Reflexive Modernization. 1. ${ }^{\text {a }}$ edición. California: Stanford University Press, 1994, pp. 1-55.

- Self-Dissolution and Self-Endangerment of Industrial Society: What Does This Mean? En BECK, Ulrich; GIDDENS, Anthony y LASH, Scott. Reflexive Modernization. 1. edición. California: Stanford University Press, 1994, pp. 174-183.

CASTEL, Robert. La metamorfosis de la cuestión social. 1. a edición. Buenos Aires: Paidós, 1997.

CASTELLS, Manuel. The Information Age: Economy, Society and Culture. The Power of Identity, Volume 2. 1. ${ }^{\text {a }}$ edición. Oxford: Blackwell, 1997.

FARINETTI, Marina. ¿Qué queda del movimiento obrero? Las formas del reclamo laboral en la nueva democracia argentina. Trabajo y Sociedad, 1999, n. ${ }^{\circ}$ 1, http://habitantes.elsitio.com/ proit/zmarina.htm.

GARRETÓN, Manuel Antonio. La transformación de la acción colectiva en América Latina. Revista de la CEPAL, 2002, n. ${ }^{\circ}$ 76, abril, pp. 7-24.

KESSLER, Gabriel. Redefinición del mundo social en tiempos de cambio. Una tipología para la experiencia de empobrecimientos. En SVAMPA, Maristella. Desde Abajo. La Transformación de las identidades sociales. 1. a edición. Buenos Aires: Biblos, 2000, pp. 25-50.

LE FUR, Alicia. El asambleísta ¿un nuevo sujeto político? En AA.VV. ¿Qué son las asambleas populares? 1. ${ }^{a}$ edición. Buenos Aires: Peña Lillo-Continente, 2002, pp. 34-43.

Linz, Juan. La quiebra de las democracias. 1. ${ }^{a}$ edición. Buenos Aires: Alianza, 1991.

Manin, Bernard. Metamorfosis de la representación. En Dos SANTOS, Mario. ¿Qué queda de la representación? 1." edición. Caracas: CLACSO-Nueva Sociedad, 1992, pp. 9-40.

MCADAM, Doug; MCCARTHY, John y ZALD, Mayer. Movimientos sociales: perspectivas comparadas. 1. a edición. Madrid: Istmo, 1999.

- Oportunidades, estructuras y procesos enmarcadores: hacia una perspectiva sintética y comparada de los movimientos sociales. En MCADAM, Doug; MCCARTHY, John y ZALD, Mayer. Movimientos sociales: perspectivas comparadas. 1. ${ }^{a}$ edición. Madrid: Istmo, 1999, pp. 21-46.

Morlino, Leonardo. Democracy Between Consolidation and Crisis. 1. ${ }^{a}$ edición. Oxford: Oxford University Press, 1996.

O’DONnELL, Guillermo. Accountability horizontal. Revista Ágora, 1998, n. ㅇ 8, pp. 5-34.

Panebianco, Ángelo. Modelos de partido. 1. ${ }^{a}$ edición. Madrid: Alianza, 1990.

REMmER, Karen. Nuevas perspectivas teóricas sobre la democratización. Revista Ágora, 1996, n. ${ }^{\circ}$ 5, pp. 239-260.

Rosanvallon, Pierre. La nueva cuestión social. 1. a edición. Buenos Aires: Manantial, 1995.

Rossi, Federico. Las Asambleas Vecinales y Populares en la Ciudad de Buenos Aires. Informe de resultados parciales y preliminares de la observación en profundidad de dos casos modélicos. Buenos Aires, 2002, mimeo. 
FEDERICO MATÍAS ROSSI
216 CRISIS DE LA REPÚBLICA DELEGATIVA. LA CONSTITUCIÓN DE NUEVOS ACTORES
POLÍTICOS EN LA ARGENTINA (2001-2003): LAS ASAMBLEAS VECINALES Y POPULARES

- Aparición, auge y declinación de un movimiento social: Las asambleas vecinales y populares de Buenos Aires, 2001-2003. European Review of Latin American and Caribbean Studies, 2005, n. $^{\circ} 78$, en prensa.

Rossi, Federico; PÉREZ, Germán y ARMelino, Martín. ¿Autogobierno o Representación? La experiencia de las asambleas en Argentina. Revista de Ciencias Sociales, 2003, n. ${ }^{\circ} 14$, agosto, pp. 175-205.

SCHUSTER, Federico et al. La trama de la crisis. Modos y formas de protesta social a partir de los acontecimientos de diciembre de 2001. Buenos Aires: Informes de Coyuntura n. ${ }^{\circ} 3$, Instituto de Investigaciones Gino Germani, Facultad de Ciencias Sociales, Universidad de Buenos Aires, 2002.

SVAmPA, Maristella. Introducción. En SvAmPA, Maristella. Desde abajo. La transformación de las identidades sociales. 1. ${ }^{a}$ edición. Buenos Aires: Biblos, 2000, pp. 9-24.

TARROW, Sidney. El poder en movimiento. Los movimientos sociales, la acción colectiva y la politica. 1. ${ }^{a}$ edición. Madrid: Alianza, 1997.

Weber, Max. Economía y Sociedad. 12. ${ }^{a}$ edición. México: Fondo de Cultura Económica, 2002. 